\title{
Where is There Wisdom to be Found in Ancient Materials Technologies?
}

\section{Philip Ball}

For its innovations in science and technology, the reputation of the Mayan culture is on the rise. The Mesoamerican culture that flourished in Mexico, Guatemala, and the surrounding regions between $\mathrm{AD} 200$ and 1000 has been long known to have had a sophisticated understanding of astronomy and mathematics (including the concept of zero), and recently the ziggurat at Chichen Itza has been interpreted as an example of acoustic engineering that uses Bragg scattering from the steps to mimic the call of a sacred bird: a preColumbian photonic crystal.

Another technological triumph of the Maya is the extraordinary blue pigment used for murals, a material that still retains its azure brilliance after centuries of exposure to the elements. It has long been recognized to be a composite substance-a natural dye (indigo) mixed with clay-and recent work has shown that the indigo molecules form a highly stable surface complex with the aluminosilicate sheets of the clay, slotting away the organic substance within slit-like channels in the inorganic matrix and protecting it from acids and alkalis. ${ }^{1}$ This trick has attracted interest from chemical companies as a way to make durable, metal-free, environmentally benign paints and coatings.

No one can suppress a twinge of envy when their rivals report an ingenious innovation that they wish they had thought of first, or the chagrin when their clever new material turns out to have been preempted five years ago in the patent literature. But when the ingenuity and foresight comes from a civilization that is several centuries old, scientists are invariably delighted. There is a satisfaction in the humbling discovery that the researchers of an earlier era knew much more than we thought.

The history of science is full of such "pre-discoveries" and demonstrations of antique virtuosity. Indeed, outside the laboratory it is a common complaint that our ancestors knew more than we do.
Thomas Jefferson (not to mention Cicero) is invoked as witness to the modern degeneration of political rhetoric and discourse; some modernist paintings have begun to fade when the paint was scarcely dry, while Jan van Eyck's masterpieces from the 15th century remain as lustrous and vivid as ever.

No one, to my knowledge, has suggested that today's materials technologists are less able or informed than their historical predecessors. But there has been a recent cluster of instances in which modern methods have revealed fresh reasons for appreciating just how clever ancient artisans and technologists were. Introductions to nanotechnology often cite Michael Faraday's experiments with gold sols as the practical beginnings of the field, but colloidal gold, prepared from the alchemical aurum potabile made by dissolution of the metal in nitric and hydrochloric acids, goes back further than that. A recipe for the ruby-red solution is recorded in 1685 by the German glassmaker Andreas Cassius, and his contemporaries knew how to trap the glorious color ("Purple of Cassius") in silica glass. But that art was known even to the Romans, who made beautiful objects such as the fourth-century Lycurgus Cup (now in the British Museum). Like the recipe for the fabulous Tyrian purple dye, this secret was lost to the West with the fall of Rome.

Nanotechnologists can now also claim ancestry among the potters of Renaissance Italy. The ceramic ware made in the Umbrian town of Deruta in the 15th and 16th centuries sported distinctive metallic and iridescent glazes that were shown a few years ago to contain nanoparticles of copper and silver ${ }^{2,3}$ (see Figure).

A recipe for these nanoparticulate glazes appears in the 16th-century handbook Li tre libri dell'arte del vasaio by the Italian artisan Cipriano Piccolpasso. It tells the potter to mix copper and silver salts with vinegar, ochre, and clay and apply them to the surface of already glazed pottery. The modern study shows that this was a delicate and precisely controlled process; for example, the ratio of $\mathrm{Cu}(\mathrm{I})$ to $\mathrm{Cu}$ (II) ions is crucial to the luster effect.

In part, such examples may come to light not so much through new information about what these historical technologists were doing, as by the emergence of a conceptual framework that makes a longknown technique seems suddenly like the anticipation of a new trend. The relative softness of lime-based mortars used for stonework until the 19th century could be seen as a defect relative to modern cementbased materials. But from the contemporary perspective of smart buildings, the older mortar can be viewed as adaptive, allowing a building to accommodate a degree of ground subsidence or of expansion caused by moisture absorption in freshly baked clay bricks. This benefit was, of course, fortuitous and barely appreciated in the past; now materials technologists are seeking such solutions by design.

Another historical "lesson" - this one, too, now embraced within the field of nanoparticulate technologies-was reported recently from the art of ancient metallurgy. Jonah Erlebacher and coworkers from the Johns Hopkins University drew on the experience of medieval and Incan goldsmiths to prepare gold membranes with nanoscale pores of controlled diameters, which might find uses in catalysis and separation technologies. ${ }^{4}$

The synthesis that Erlebacher and coworkers have developed is based on the ancient technique called depletion gilding, by which means objects made from gold alloy were given the appearance of pure gold. It was a good way to fake great wealth, although the value as a means of peddling counterfeit gold would have been limited: medieval goldsmiths knew well enough how to measure the density of metals using Archimedes' method.

In depletion gilding, an object made of a gold-silver or gold-copper alloy was treated with an etchant to remove the cheaper and less inert metal from the surface layer, leaving behind a microscopically porous layer of gold that was then smoothed and burnished. The etching was usually carried out with nitric acid, which was known in medieval Europe since at least the 13th century. Erlebacher and co-workers used this same etching process on commercial white-gold leaf (a 1:1 alloy of silver and gold) and found that because the process involves the dynamic migration of gold atoms rather than simple excavation of the other metal, the diameter of the resulting nanopores increases with increasing immersion time.

This sort of precise control of microstructure was, of course, totally irrelevant to medieval goldsmiths-not only were 
they ignorant of how the procedure worked, but they obliterated the porous texture during burnishing. All the same, the historical technique was the direct inspiration for the modern one: microstructural studies of depletion gilding in the 1960s and 1970s identified the bicontinuous "porous membrane" structure, which awakened the interest of Erlebacher and co-workers when viewed against the backdrop of a desire for precisely engineered nanoporous materials.

As in the case of the Mayan blue pigment, such convergence of new and old interests invites us to shower praise on the skills of the ancient technologists. There is nothing wrong with that. But the tendency to present such instances as examples of prescience is almost always misguided. This can result in crude and obvious anachronism, such as when an article of mine on the potters of Deruta was given the title (and I confess that I did not object at the time) "Renaissance Potters were Nanotechnologists." This simply has no meaning, in the same way that it is meaningless to say that, for instance, Tibetan devotional music is composed in a "minimalist" style. There is a critical difference between saying that tempering of iron with hammer and anvil modifies the distribution of dislocations and saying that medieval blacksmiths were defect engineers.

More insidious, however, is the kind of interpretation that attempts to forge links with contemporary science for the purposes of a positivist historical agenda. This was often done in the 19th century, and it resulted in, for example, the denigration of alchemy in the history of chemistry and the concomitant suppression of the alchemical interests of Newton and Boyle. It is still common to find the Copernican theory presented as an attempt at rootand-branch reform of astronomy, rather than as a practical method for simplifying astronomical calculations.

But as far as "materials culture" is concerned, there has been an equal tendency among some documenters of science history (I will not say "historians of science") to go to the opposite extreme: to deny that the inventiveness of the Mayans or the Egyptians or the alchemical artisans had anything to do with real science because it was produced by blind trial and error or mindless recipe-reading, without anything like a respectable theoretical framework to justify it. This is the position, for example, of British biologist Lewis Wolpert, who writes:

Science produces ideas whereas technology results in the production of

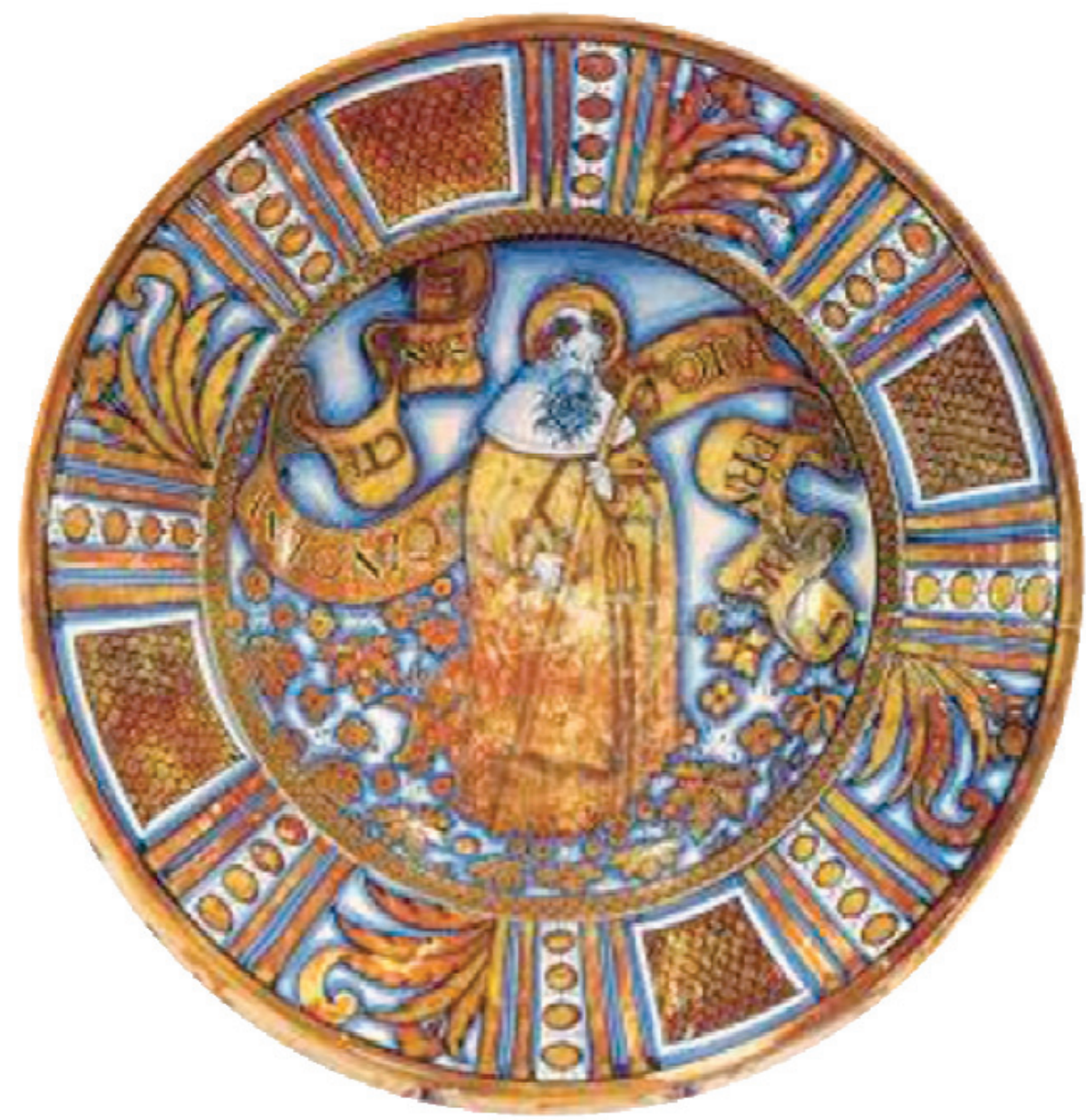

Sixteenth-century lustre plate from Deruta. Courtesy of Museo Regionale della Ceramica di Deruta.

usable objects. Technology-by which I mean the practical arts-is very much older than science. Unaided by science, technology gave rise to the crafts of primitive man, such as agriculture and metalworking, the Chinese triumphs of engineering, Renaissance cathedrals, and even the steam engine. Not until the nineteenth century did science have an impact on technology. ${ }^{5}$

Not only does this turn into "non-science" huge swaths of what commonly passes for science today, but it evinces a contempt for any kind of historical perspective on science at all.

Thus, the high-resolution optical microscope did not suddenly make metallurgy a science-but it did, as Cyril Stanley Smith once pointed out, tell the metallurgist more about the history of that science (and art) than any documentary records could:

Microstructures... instantly reveal to a knowing eye the technical history of making the object. Such records are in a universal language, and they are free from the distortion that inevitably accompanies passage through a human mind. Through such records, I have communicated with dozens of craftsmen, including a Luristan smith of 800 $\mathrm{BC}$, a bronze founder of Shang, China, an ancient Greek goldsmith, and a 13thcentury Japanese swordsmith. ${ }^{6}$

Smith, one of the most accomplished translators of historical documents of materials culture, understood completely how one might acquire deep respect for the knowledge and skills of past cultures without forcing them into a 20th-century vessel. Technological innovation-one of the key components of science, and not an adjunct to it-has in the past relied on experimentation, but not aimlessly. If a theory stimulates experiment and careful observation, it surely does not detract from the "scientific" nature of that work if the theory proves later to be utterly wrong. (Vermilion, or artificial cinnabar, might well have been the product of the 
Islamic alchemists' sulfur-mercury theory of metals, which even provided quantitative, albeit incorrect, predictions for the amounts of sulfur and mercury required in the mix.)

But it would be wrong in any event to insist that experimentation should be grounded in rigorous theory before it deserves to be categorized as science. "Aesthetic curiosity," said Smith, "is the very root of all discovery.... Discovery is art, not logic, and new discoveries have to be cherished for reasons that are far more like love than purpose."7 Could it, after all, be anything other than love of their materials that enabled ancient craftspeople to make discoveries that we are only now, with our modern techniques and instruments, beginning to understand? Science was of no help to 19th-century French chemists when they attempted to reproduce the opalescent celadon and Jun glazes of Chinese potters of the Song dynasty (960-1279), with their "white clouds" glistening against a "blue sky."

Neither should we picture these ancient technologists throwing any old ingredients into the pot in a rapture of creative excitement. Modern combinatorial methods of materials discovery show how quickly the permutations of ingredients become overwhelming if concocted with- out any guiding intelligence. Illustrations of ancient Egyptian kiln design attest to the systematic nature of experiments that optimized firing conditions, while ancient and medieval artisans' manuals often record procedures with great care and quantitative detail. "[T]he most remarkable aspect of the chapters of Theophilus [in his medieval work On Divers Arts] on glass," writes materials scientist Ian Freestone, "is just how frequently and in what detail they prove accurate." 8 Some of these experimenters, at least, knew how to keep good laboratory notes and made thorough checks of how older recipes stood up in practical terms.

On top of all this, the feedback between experiment and outcome depended on the social context of the work. The Egyptian, Incan, and Western medieval artisans were prepared to devote so much effort to getting the right materials because their artifacts were mostly being made for religious and devotional purposes. "Separation of aesthetics from technique, of tools from signs, of technofunction from sociofunction," said David Kingery, "is an artificial construct of scholars searching for a reductionist mode of analysis."

Thus we should continue to be inspired and delighted by the materials prowess of ancient cultures, but we should be wary of placing their achievements in a modern context. They made those things for themselves, not for us.

\section{References}

1. L.A. Polette, G. Meitzner, M.J. Yacaman, and R.R. Chianelli, Microchem. J. 71 (2002) p. 167.

2. W.D. Kingery and P.B. Vandiver, Ceramic Masterpieces (Free Press, New York, 1986) p. 111.

3. J. Pérez-Arantegui, J. Molera, A. Larrea, T. Pradell, M. Vendrell-Saz, I. Borgia, B.G. Brunetti, F. Cariati, P. Fermo, M. Mellini, A. Sgamellotti, and C. Viti, J. Am. Ceram. Soc. 84 (2) (2001) p. 442. 4. Y. Ding, Y.-J. Kim, and J. Erlebacher, Adv. Mater. 16 (21) (2004) p. 1897 (DOI: 10.1002/ adma.200400792).

5. L. Wolpert, The Unnatural Nature of Science (Faber \& Faber, London, 1992), p. 25.

6. C.S. Smith, A Search for Structure (MIT Press, Cambridge, MA, 1981).

7. C.S. Smith, A Search for Structure (MIT Press, Cambridge, MA, 1981), pp. 351, 347.

8. I.C. Freestone, in Materials Issues in Art and Archaeology III, edited by P.B. Vandiver, J.R. Druzik, G.S. Wheeler, and I.C. Freestone (Mater. Res. Soc. Symp. Proc. 267, Pittsburgh, PA 1992) p. 744

9. W.D. Kingery, ed., Learning From Things (Smithsonian Institution Press, Washington D.C., 1998), p. 200

Philip Ball is a science writer and a consultant editor for Nature. 